\title{
Development of the Nursing Section of the Community Health Team
}

\author{
JOHN C. HASLER,* M.B., M.R.C.G.P., D.A., D.C.H.; P. M. R. HEMPHILL,* M.A., M.B., B.CHIR. \\ T. I. STEWART,* M.B., M.R.C.G.P., D.C.H. ; NORA BOYLE, † S.R.N., S.C.M.; AUDREY HARRIS, † S.R.N. \\ ELIZABETH PALMER, S.R.N.
}

Brit. med. .., 1968, 3, 734-736

The need for integration of community medical workers has been stressed in recent years, and the necessity for a team approach has become obvious. In a recent survey Lisbeth Hockey (1966) has said that district nurses "frequently lacked full information about their patients' condition and treatment" and "had very little contact with general practitioners, hospitals, health visitors, or other workers." She adds, " most doctors are ignorant about district nurses' qualifications and the help they could give," and "nearly half the doctors had difficulty in contacting district nurses." The development of a health team requires radical rethinking of the duties of each member.

This practice has been developing an integrated team for the past two years, and this preliminary report deals with the activities of the nursing members of the team on the district and in the group practice centre. It is hoped to publish a subsequent report on the further integration of these services and an experimental direct link with the hospital service. In this paper we are not dealing with the work of the health visitor, though she is an important member of the team.

We wish to place on record the co-operation we have received from the County Medical Officer and from the County Nursing Officer for Oxfordshire, without which the district nursing development would not have been possible.

The team now consists of three general practitioners, three administrative staff, one district nursing sister, one health visitor, two treatment-room sisters, and one district nursing auxiliary. The district nursing sister, health visitor, and nursing auxiliary are attached local health authority staff. The population served is approximately 6,800 in a semi-urban and rural area consisting mainly of social classes 1,2 , and 3 . There is a large amount of obstetric and paediatric work. The doctors have access to maternity and medical beds, and virtually no domiciliary confinements are undertaken. Two of the doctors hold hospital sessions in rheumatology and anaesthetics.

The district work is done by the district nursing sister, assisted by the nursing auxiliary. The nursing and technical work at the group practice centre is done by two part-time sisters in the treatment room, so providing full-time cover ( $43 \frac{1}{2}$ hours per week). Ideally the nurses should be interchangeable between treatment room and district, but the present scheme works satisfactorily.

\section{District Work}

Our district nursing sister is in many ways comparable to a hospital ward sister. For the past 18 months she has been doing work traditionally done by doctors, while some of the nursing work has been delegated to the auxiliary. The district

- General Practitioner, Sonning Common, Oron. † District Nursing Sister, Sonning Common, Oron. nursing sister is similar to the nurse described by Weston Smith and Mottram (1967), except that ours, being employed by the local health authority, is also concerned with traditional work. Being fully attached, she has no geographical area as such, but works only for our patients, except on rare occasions when she is required to relieve neighbouring district nurses. Her work, analysed in Table $I$, consists of :

(1) Diagnostic and Therapeutic Visits.-(a) First or assessment visits: infectious diseases, influenza, tonsillitis, certain emergencies and "vague" calls. (b) Revisits: some respiratory illness, infectious diseases, acute lumbago and sciatica, hospital discharges, cerebrovascular disease. (c) Chronic visiting: mainly geriatric, performed according to the need of the patient and not according to age. Some of the visits involve collection of blood and other pathological specimens, in addition to clinical observation.

(2) Nursing Visits.-Routine district nursing visits. These may be combined with visits in category 1 above.

The decision on whether the sister makes a first or assessment visit rests with one of the doctors. All new requests for home visits are screened by the senior secretary, who is an S.R.N., in consultation with the doctors. The doctors and sister then decide at the daily conference which cases are suitable for her, and she reports back later in the day to the doctor concerned. If the doctor, sister, or patient is anxious the doctor will see the patient.

Revisits are also discussed at the morning case conference. The sister may have taken over the care of the patient, or she may be visiting alternately with the doctor. She reports briefly after each chronic geriatric visit. On all occasions records are made in the N.H.S. notes by her-an essential part of the scheme. The doctors also make notes at each attendance and visit, so that a full and continuous record is available.

The traditional nursing work is also discussed at the case conference, and where appropriate the district nursing sister delegates it to the auxiliary. If during the course of her work the auxiliary is anxious about a patient, she reports to the nursing sister, who decides what action to take.

In this way much work that a doctor might otherwise have to do is coped with satisfactorily. In a small number of cases the doctor has to follow up the sister's initial visit on the same

TABLB 1.-District Nursing Sister's Visits, fanuary 1967 to May 1968 Diagnostic and therapeutic

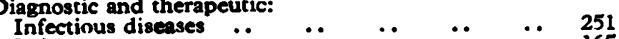
$\begin{array}{lllllll}\text { Infectious diseases } & \ldots & \ldots & \ldots & \ldots & \ldots & 251 \\ \text { Infeetions } & . . & . & & & \end{array}$ $\begin{array}{llllr}\text { Accidents and emergencies } \because & \because & \because & \because & 18 \\ \text { Hospital discharges and postoperativ } 2 \text { follow-up } & \cdots & 42\end{array}$

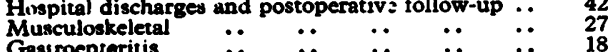
$\begin{array}{lllllll}\text { Gascroenteritis } & \because & \because & \because & \because & \ldots & 18 \\ \text { Advice } & & & \end{array}$ Advice..j (venepuncture, ëtc.) (often includè

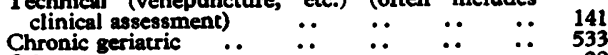

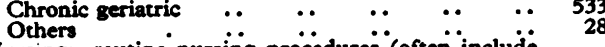

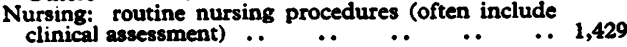

Notes: The district nursing auxiliary was appointed only towards the end of this period. Many of the visits overlap in their purpose, so a classification of this kind is dificult. This period included a total of 21 weeks' absence for holidays, sick leave, and study leave. 
day. In some instances, if the patient is a child, the mother and patient are brought to the doctor by the sister for an immediate consultation; but frequently the sister's advice, occasionally supported by a simple remedy prescribed by the doctor, suffices until the patient is well enough to come to the doctor at the surgery.

\section{Treatment Room}

The sisters at the group practice centre carry out a wide range of procedures, including a fair amount of minor casualty work, as the practice is 5 miles $(8 \mathrm{~km}$.) from a casualty department. The analysis of their work is shown in Table II, and consists of : (a) Nursing: injections, dressings, immunizations, vaccinations, oral polio, suturing and removal of sutures, reception of casualties and emergencies, conducting antenatal clinics. (b) Technical: ear syringing, pathology collection (including blood), urine testing, electrocardiography, Wright peak flow meter, weighing, and measuring. (c) Dispensing: dispensing to rural patients, stocking dispensary and doctors' cars. (d) Advice to patients in person and by telephone.

Many patients make appointments direct with the sister; others are referred from the dootor at the time. In addition any patient who wants advice but does not wish to bother a doctor can speak to the sister. If she is not certain what action to take she gets advice from a doctor, but at the same time she is encouraged to take responsibility where appropriate. She can also help the office staff if they require advice when all the doctors are out. She makes notes in the N.H.S. records in the same way as the doctors and district nursing sister.

It will be seen that the amount of work the treatment-room sisters perform is considerable, and most of this was previously done by doctors.

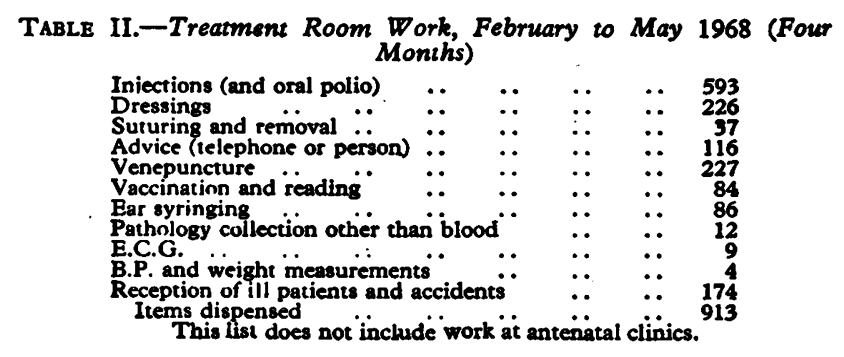

\section{Advantages}

Firstly, the doctor can now spend adequate time with the patient and consult in a less hurried manner. The patient appreciates this, and tends to return less often. Appointments are normally made at the rate of six an hour.

Secondly, the range of work widens, and its standard improves. Necessary pathological investigations are made without hesitation, and minor surgery is undertaken more readily. The satisfaction to the doctors of being able to concentrate on the work which they alone can do is greater, and the nurses appreciate being able to take responsibility equal to their experience. On a number of occasions important diagnoses have been made more rapidly, particularly when the district nursing sister has drawn the doctor's attention to a patient unaware of his condition.

The working day is changed from a hurried rush with minor irritations to an organized pattern of work. This means better service for the patient, and possibly longer life for the doctor.

\section{Safeguards}

Firstly, there must be absolute trust and impeccable communication between the various members of the team, and all consultations and work done must be recorded in writing. A break of 40 minutes is made between morning consulting sessions, and during part of this time a case conference is held at which all members of the clinical staff are present.

Secondly, the nurses must be experienced and competent. As Weston Smith and Mottram say, "This is no position for the newly qualified S.R.N." All our nurses have children of their own, which is an additional asset.

Thirdly, the doctors must be satisfied that the nurses know how to perform technical manœuvres and what they are required to do. By special arrangement the treatment room nurses were attached to the local pathology laboratory, and one was attached to the casualty department, before starting work in the practice.

\section{The Future}

Weston Smith and Mottram preferred their own nurse to do diagnostic and therapeutic work on the district. We think it is preferable to have local authority nurses, because it is undesirable that two different kinds of nurse should deal with the same patient ; besides, duplication is avoided. Nursing procedures and clinical assessment can of ten be combined. We think attachment schemes as such are only a halfway step, and that qualified nurses should develop in the way we have indicated, themselves delegating less important work where possible. Warin (1968) has stated that a successful attachment scheme has shown the nced for an increase in the establishment both of health visitors and of district nurses. We think that some of this increase should be in State-enrolled nurses and auxiliaries, who can release the health visitors and district nurses for more responsible work.

In order to operate effectively, all members of the team must work from one central building, either a health centre or a group practice centre. We firmly believe that a scheme of this kind would increase the attractiveness of general practice and district nursing-an important consideration, as there is a shortage of recruits in both fields.

We believe that just as every medical student should see something of general practice, so every pupil nurse should ser. something of community medicine. We agree with Westen Smith and Mottram that a post-registration course for generalpractice nurses of the order of six months should be instituted.

The planning of future medical services must be integrated. The community health team should be viewed in correct relationship with hospital and local authority services, and not as an isolated group. This would perpetuate the present artificial triad. There must be more flexibility among personnel.

We must attempt to rationalize the services in the next decade; both hospitals and general practice will be even more short of doctors than they are now. Peacock and Shannon (1968), two economists, have attacked the implication that "the only way in which patients can obtain a better standard of service" is on the assumption that "more doctors mean healthier patients" (National Institute of Economic and Social Research). They say, "It is plain that many doctors are strongly opposed to the delegation of tasks to lesser-trained auxiliaries, although this would allow them to use their own skills to greater advantage." And they continue, "We suggest that to expect special exemption from the forces of change is bound to lead to disappointment, so long as resources available for health compete with other uses to which government might put them, and while changes in the incidence of illness and disease call for new skills and techniques."

We sincerely believe that teamwork of the kind we have described is the main factor that will enable the standard of general practice to improve in the face of an increasing workload and allow the community health service to play its full part in medical care in the future. 
We wish to thank Dr. M. J. Pleydell, County Medical Officer, and Miss E. Richards, County Nursing Officer for Oxfordshire, for their help and encouragement with the project. We also wish to thank Dr. F. Hampson, director of pathology, and Dr. D. Robertson Smith, consultant haematologist, Royal Berkshire Hospital, for allowing the practice nurses to attend their department; also the matron and sister in charge of casualty, Battle Hospital, for giving one of the nurses the same opportunity.
REPBRENCES

Hockey, Lisbeth (1966). Feeling the Pulse. London.

Paige, D., and Jones, K. (1966). Health and Welfare Services in Britain in 1975, National Institute of Economic and Social Research,

Peacock, A., and Shannon, R. (1968). Practitioner, Suppl. No. 6, p. 9. Smith, J. W., and Mottram, E. M. (1967). Brit. med. F., 4, 672.

Warin, J. F. (1968). Brit. med. F., 2, 41.

\title{
Regional Postgraduate Medical Centres*
}

\author{
JOHN LISTER,† M.D., F.R.C.P.
}

The need for regional postgraduate education was stressed at the 1961 conference in Oxford, and the result of that conference has been the establishment of a large number of postgraduate centres throughout the country.

The time now seems appropriate to appraise the achievements of these centres and to see how the momentum of postgraduate activity can be maintained and guided on the most effective lines.

In the belief that all those running regional centres have a number of common problems, I had a questionary prepared and sent to 311 clinical tutors throughout England, Wales, Scotland, and Northern Ireland, their names being supplied by the Postgraduate Medical Federation. The questionary asked details of the tutor's own specialty, the accommodation available to him, and the methods of financing any capital expenditure and of providing for running costs. The tutors were also asked for information about their staff, library facilities, catering facilities, and the various types of meeting they hold. They were also asked to estimate the weekly time involved in their work as tutor and to make any other relevant remarks.

Of the 311 questionaries sent out 221 (71\%) were returned and revealed that throughout the country there are at least 74 existing centres, either purpose-built or in converted premises ; 37 planned centres, and 53 making use of improvised hospital accommodation. Twenty-one tutors replied that they were psychiatrists and not responsible for general teaching, and 36 others returned their questionaries with explanatory letters indicating why they did not actually apply to their appointments-several of them being involved in teaching hospitals rather than regional hospitals.

\section{Specialty of Clinical Tutors}

The specialties of the 221 tutors who replied are shown in Table I. It was found that the number of hours they devoted to running their centres each week varied from 1 to 20 , the average being $4 \frac{1}{2}$.

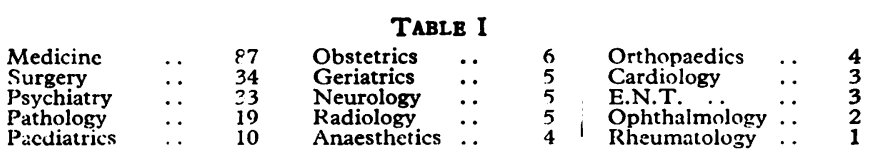

\section{Regional Distribution of Centres}

Table II shows the regional distribution of existing and planned centres. It is appreciated that the list may be incom-

† Clinical Tutor, W:ndsor Group of Hospitals.

* Paper read at Convention of Clinical Tutors at the Royal College of Physicians of London 11 July 1968. plete, since the statistics have been prepared from the data on the questionaries actually returned. Nevertheless, the achievement in the Birmingham Region would appear outstanding and, even allowing for the varying size of regions, there is evidence of considerable variation in facilities from onc region to another.

\begin{tabular}{|c|c|c|c|c|c|c|}
\hline & \multicolumn{5}{|c|}{ TABLE II } & \multirow[b]{2}{*}{ Total } \\
\hline & & & & Existing & Planned & \\
\hline $\begin{array}{l}\text { Birmingham } \\
\text { East Anglia } \\
\text { Leeds } \\
\text { Liverpooi } \\
\text { Manchester } \\
\text { N.W. Metropoli } \\
\text { S.W. Metropoli } \\
\text { N.E. Metropolit } \\
\text { S.E. Metropolit } \\
\text { Newcastle } \\
\text { Oxford .. } \\
\text { Sheffield } \\
\text { Wessex ... } \\
\text { South-Western } \\
\text { Wales } \\
\text { Scotland } \\
\text { Ireland }\end{array}$ & $\begin{array}{l}\because \\
\because \\
\because \\
\text { litan } \\
\text { itan } \\
\text { itan } \\
\tan \\
\because \\
\because \\
\because \\
\because \\
\because \\
\therefore\end{array}$ & $\begin{array}{l}\because \\
\because \\
\because \\
\because \\
\because \\
\because \\
\because \\
\because \\
\because \\
\because \\
\therefore\end{array}$ & 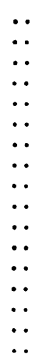 & $\begin{array}{r}12 \\
3 \\
4 \\
4 \\
8 \\
5 \\
4 \\
5 \\
7 \\
3 \\
2 \\
5 \\
2 \\
1 \\
6 \\
3\end{array}$ & $\begin{array}{l}4 \\
1 \\
3 \\
1 \\
3 \\
3 \\
1 \\
3 \\
2 \\
3 \\
3 \\
3 \\
4 \\
\frac{2}{1}\end{array}$ & $\begin{array}{r}16 \\
4 \\
7 \\
1 \\
7 \\
11 \\
6 \\
7 \\
7 \\
10 \\
6 \\
5 \\
5 \\
6 \\
3 \\
6 \\
4\end{array}$ \\
\hline
\end{tabular}

Many tutors commented on the kind of difficulties they have encountered when trying to obtain suitable accommodation for their centres, the following being a selection of typical remarks:

"I am negotiating for the inclusion of a separate P.G. centre in the new district hospital. As yet, the R.H.B. has refused to contribute."

“Local G.P.s and hospital staff want a centrc, but our efforts have had no results because the board is undecided about which hospital shall be developed as a district hospital. At the beginning of the campaign we were given some encouragement, only to be met by administrative stonewalling ever since. The board and the H.M.C. refuse to allow us to open a public appeal."

"We are about to launch an appeal to build a centre when the R.H.B. agree to the site."

"We haven't got a decent place to meet in. Mostly we borrow the nurses' recreation room. Our library is split up in various collections in different ward offices. There is no suitable vacant accommodation and apparently no chance of getting this H.M.C. to put up a wooden building."

And finally one unfortunate tutor complained:

"There are no bricks and no straw to make any!"

On the other hand, other tutors did comment on the great support they had received from their H.M.C.s. One stated:

"This is one of the few centres built and financed entirely by public funds. The H.M.C. is very generous in encouraging the work of this centre, which has already become a busy institution in the medical life of the town."

Others have commented on the assistance they have received in planning ingenious conversions from such unlikely buildings 